\title{
The Seismic Characteristics of Surface Ground of Zushi-Site during the 2011 off the Pacific Coast of Tohoku Earthquake
}

\author{
Takahiro Iwatate ${ }^{1}$, Nobuyuki $\mathrm{Naito}^{2}, \mathrm{Koji}_{\mathrm{Ando}}{ }^{3}$ and Yoshiya Oda ${ }^{4}$ \\ 1. Professor Emeritus, Department of Civil Engineering, Graduate School of Engineering, Tokyo Metropolitan University \& Senior \\ Research Adviser, Chishitsu Keisoku Co., Ltd, 1-1Minamiosawa, Hachioji, Tokyo 192-0397, Japan \\ 2. ARK Information Systems, Inc., 3-22-17, Shinyokohama, Kohoku-ku, Yokohama 222-0033, Japan \\ 3. Vibrant System Development Co., Ltd., 5-39-16, Nangai, Higashiyamato-shi, Tokyo 207-0014, Japan \\ 4. Department of Civil and Environmental Engineering, Tokyo Metropolitan University, 1-1Minamiosawa, Hachioji, Tokyo192-0397, \\ Japan
}

\begin{abstract}
In Tokyo Metropolitan University, the horizontal and vertical array earthquake observations has begun in June 1994 at the five stations (k1-k5) on the ground surface and bedrock (k6: -30 m depth) at Zushi-site. More than 200 medium and small earthquakes with the magnitude 5.0-7.3 were recorded between 1994 and 2012. At the 2011 off the Pacific coast of Tohoku Earthquake (EQ.3.11 $M=9.0)$, the largest surface ground acceleration $(\mathrm{k} 1=124.5 \mathrm{gal}, \mathrm{k} 6=45.5 \mathrm{gal})$ of the horizontal component was recorded. Main results were obtained as follows: (1) the surface ground motion characteristics of Zushi-site were examined using the observed data $(\mathrm{k} 1$ \& k6) of EQ.3.11, the past-observed smaller earthquakes (EQ.1 \& EQ.10.08) and aftershock (EQ.12.3), respectively. The non-liner seismic response characteristics of the surface ground at Zushi-site were verified during EQ.3.11. (2) The ground structure models were examined and identified by the modal analyses and the FEM (finite element method) identification analyses using the observed acceleration data of EQ.3.11 and the past observed smaller earthquakes. (3) Moreover, the three dimensional seismic response analyses were performed by TDAPIII (time domain 3-dimensional dynamic analysis program), using k6 for input motions and identified ground structure model, and evaluated the dynamic behaviours of the surface ground. The calculated results agreed well with the observed ones.
\end{abstract}

Key words: The 2011 off the Pacific coast of Tohoku earthquake, Zushi-site, earthquake observation, identification analysis, seismic response analysis.

\section{Introduction}

The 2011 off the Pacific coast of Tohoku Earthquake (EQ.3.11) that occurred on March 11, 2011, recorded the domestic observation history of the largest magnitude $M w=9.0$ and the hypocentral region of this earthquake extended from offshore Iwate Prefecture to offshore Ibaraki Prefecture with a length of $500 \mathrm{~km}$ and a width of $200 \mathrm{~km}$.

Tsunami waves climbed more than $10 \mathrm{~m}$ with the

Corresponding author: Takahiro Iwatate, Dr., research fields: civil engineering (seismic engineering). E-mail: rock-tak@tmu.ac.jp. maximum run-up height $40.5 \mathrm{~m}$ depending on location by this earthquake, and brought the catastrophic damages to road and railway as well as fires in the Pacific coast of Tohoku region (Iwate, Miyagi and Fukushima Prefectures) and Kanto region (Ibaragi and Chiba Prefectures). By this earthquake, dead and missing persons are more than 20,000 people.

In Tokyo Metropolitan University, the horizontal and vertical array earthquake observations have started in June 1994 at the five stations (k1-k5) on the ground surface varied with the depth of surface layer and bedrock (k6: $-30 \mathrm{~m}$ depth) at Zushi-site with 
various soil conditions.

More than 200 medium and small earthquakes (smaller earthquakes) with the magnitude 5.0-7.3 were recorded between 1994 and 2011 before EQ.3.11. In EQ.3.11, the largest surface ground acceleration (124.5 gal) of the horizontal component was recorded at k1 station. And after EQ.3.11, many aftershocks (smaller earthquakes) were recorded.

The objectives of this study are as follows:

(1) To clarify the dynamic characteristics of the ground of Zushi-site [1, 2] during EQ.3.11, comparing those subjected by the past smaller earthquakes (EQ.1 \& EQ.2) and aftershock (EQ.12.03).

(2) The ground structure models of the Zushi-site were identified by the modal analysis and the FEM (finite element method) identification analysis using the observed data of EQ.3.11, EQ.1 \& EQ.2 and EQ.12.03.

(3) The seismic response analyses were performed by TDAPIII (time domain 3-dimensional dynamic analysis program) [3], using the identified models and the observed earthquake data (k6) of EQ.3.11 and EQ.12.03 for input motions.

From these results, the seismic non-linear behaviours of the surface ground of Zushi-site during the great earthquake (EQ.3.11) were verified.

\section{Earthquake Observations at Zushi-Site}

\subsection{Zushi-Site}

The city of Zushi is located in Kanagawa Prefecture, in the southern part of the Tokyo metropolitan area and is particularly high seismicity area. The city suffered severe damages during the 1923 Great Kanto Earthquake (Magnitude $(M)=7.9$ ).

Geographically, two major rivers (the Tagoe River and the Ikego River) run through the city. The city can be divided into three zones based on ground characteristics; the Holocene lowland zones along the banks and mouths of the main rivers; a zone consisting of reclaimed land near the coastline, and a hill zone (Fig. 1-a). The geological sections of the site along and across the Tagoe River are shown in Figs. $1-\mathrm{b}$ and $1-\mathrm{c}$.

\subsection{Earthquake Observation Points}

Seismic array observation has commenced in June, 1994, at five ground surface stations (designated by k1-k5). In 1998, one station in the borehole designated by k6 was added. Stations, k1, k2, k4 and k5 have located on the surface of Holocene low-land along the two rivers (Tagoe and Ikego), k3 was located on the outcrop rock, and $\mathrm{k} 6$ was located on bedrock (with $-30 \mathrm{~m}$ depth) just below k1 (Fig. 1).

Tow geological cross-sections (A-A' and B-B') along and across Tagoe River of Zushi-site are shown in Fig. 2. The bedrock with the shear wave velocity ( $V s \mathrm{~m} / \mathrm{s}$ ) greater than $400 \mathrm{~m} / \mathrm{s}$ occurs at a depth of -30 $\mathrm{m}$ at $\mathrm{k} 1,-12 \mathrm{~m}$ at $\mathrm{k} 2,-15 \mathrm{~m}$ at $\mathrm{k} 4$, and $-7 \mathrm{~m}$ at $\mathrm{k} 5$, respectively.

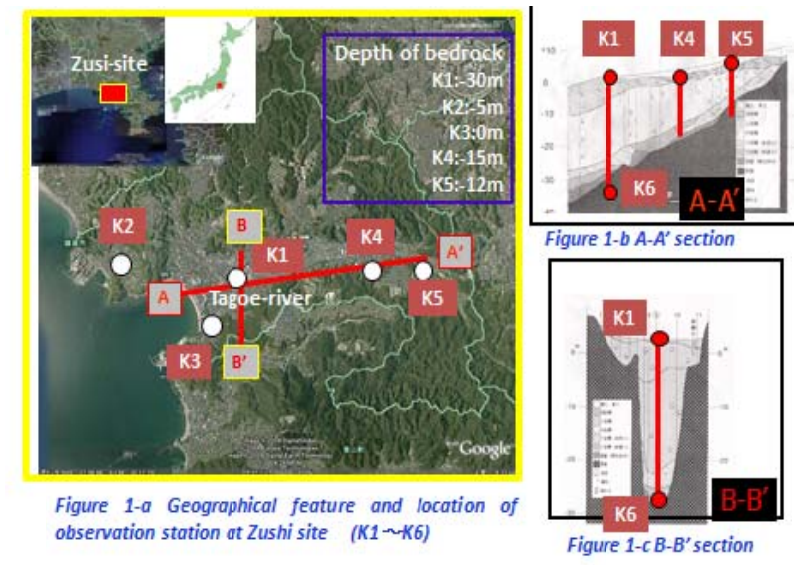

Fig. 1 Earthquake observation point at Zushi-site.

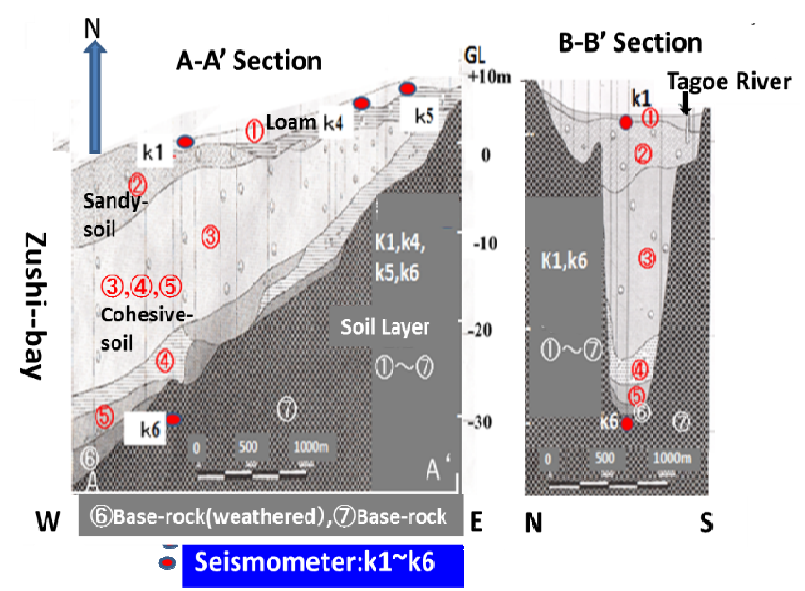

Fig. 2 The geological sections (A-A' \& B-B') of Zusi-site along and across the Tagoe River. 


\subsection{Earthquake Observation Data}

(1) More than 200 medium and small earthquakes (smaller earthquakes) with the magnitude $M=5.0-7.3$ were recorded between 1994 and 2012, including the 1998 Tokyo Bay Earthquake (EQ.1: $M=5.4$ ), the 1999 NW Chiba Earthquake (EQ.2: $M=5.1$ ) before EQ.3.11.

(2) Fig. 3 shows the epicentres of EQ.3.11, the past observed smaller earthquakes EQ.1, EQ.2, EQ.10.8 $(M=4.7)$ and the aftershock occurred on 3rd, December, 2011 (EQ.12.3, $M=5.2$ ).

(3) Fig. 4 shows the observed horizontal accelerations in NS direction (NS-component) at the surface (k1) and bed-rock (k6), in case of EQ.10.8, EQ.3.11 and EQ.12.3, respectively.

From these figures, the main results were obtained as follows:

(1) In the past-observed smaller earthquakes, the maximum accelerations of these earthquakes were small less than 100 gal and these duration times were short less than 60 seconds. The maximum acceleration value is $75.4 \mathrm{gal}$ for horizontal component and $13.75 \mathrm{gal}$ for vertical one of Sagami-bay Earthquake (07/03/95: $M=5.6)[1,2,4]$;

(2) In EQ.3.11 $(M=9.0)$, the recorded data are quite different from the past recorded ones, that is, the duration time was more than 300 seconds and the maximum horizontal acceleration (NS component)

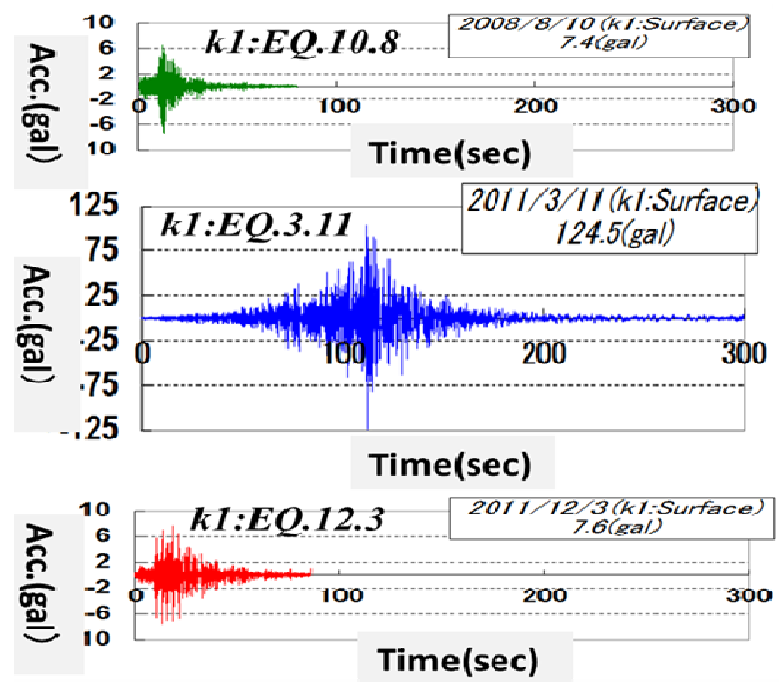

was recorded at $\mathrm{k} 6$, respectively;

(3) The after-shock (EQ.12.3) is also smaller and the duration time is short less than 40 seconds.

\subsection{The Surface Ground Characteristics of Zushi-Site}

In order to examine the surface ground motion characteristics of Zushi-site (k1 \& $\mathrm{k} 6)$ during earthquakes, the observed data (k1 \& k6) of the past-observed smaller earthquake (EQ.10.08), and ones of EQ.3.11, and ones of aftershock (EQ.12.03), the transfer functions $(\mathrm{T} 1(\mathrm{k} 1 / \mathrm{k} 6)$ for EQ.10.08, T2 $(\mathrm{k} 1 / \mathrm{k} 6)$ for EQ.3.11 and T3 (k1/k6) for EQ.12.03) between the surface ground $(\mathrm{k} 1)$ and the bedrock $(\mathrm{k} 6$ :

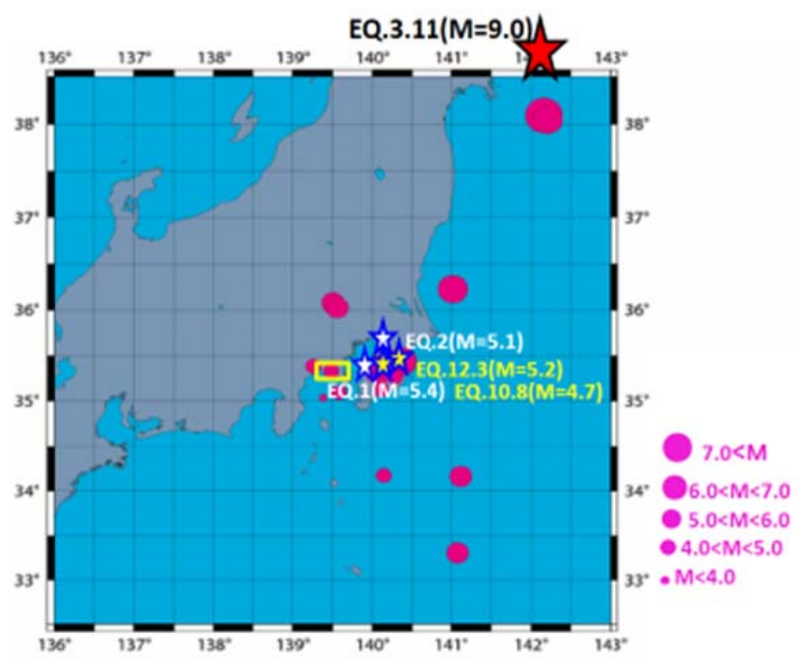

Fig. 3 The epicenters of EQ.3.11, EQ.1, EQ.2, EQ.10.8, EQ.12.3 and the past observed earthquakes (pink-dots) in 2006.

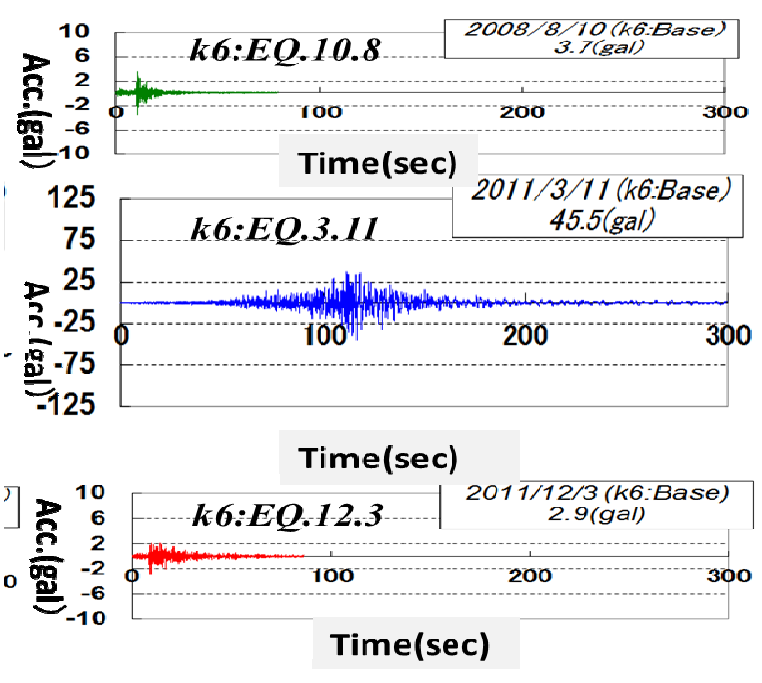

Fig. 4 The observed accelerations (k1\&k6) of EQ.10.8, EQ.3.11 and EQ12.3 (NS-component). 
$-30 \mathrm{~m})$ were estimated using these observed data, shown in Fig. 5. Comparing T2 to T1 \& T3, the main results were obtained as follows.

The predominant frequency $(f 1)$ of the surface ground was obtained about $2.31 \mathrm{~Hz}$ for T1, $1.9 \mathrm{~Hz}-2.1$ $\mathrm{Hz}$ for $\mathrm{T} 2$ and $2.31 \mathrm{~Hz}$ for $\mathrm{T} 3$, respectively. The frequency $(f 1)$ for $\mathrm{T} 2$ is about $10 \%$ smaller than that for $\mathrm{T} 1$ and $\mathrm{T} 3$. So, in case of EQ.3.11, the soil property $(V s / \mathrm{m})$ of the surface ground was decreased about $10 \%$ on an average and then the nonlinear properties of the surface ground were occurred fairly due to EQ.3.11.

\section{The Ground Structure Models Estimated} by Modal Analysis and the FEM Identification Analysis

In order to identify the ground structure model of Zushi-site more correctly, the modal analysis and the FEM identification analysis [5-7] were applied using the initial model and the observed earthquake acceleration data (k1 \& k6) of the past-observed earthquakes (EQ.1: $M=5.4$ and EQ.2: $M=5.1$ ), EQ.3.11 and aftershock (EQ.12.03).

The procedure of these analyses is as follows, shown in Fig. 6.

(1) Firstly, the initial ground structure model was made using the existing soil data, the seismic exploration test data and the micro tremor observation data $[1,2]$.

(2) Secondly, the modal analysis method to grasp the dynamic characteristics of the ground using the observed acceleration data (k6) of EQ.311 (Case2), EQ.1 \& EQ.2 (Case1), and EQ.12.03 (Case3) for input motions.

(3) Thirdly, the modal identification analysis method to carry out based on the results of the modal analysis [5].

\subsection{Modal Analysis Method}

The purpose of the modal analysis is to clarify the dynamic characteristics of the vibration system by

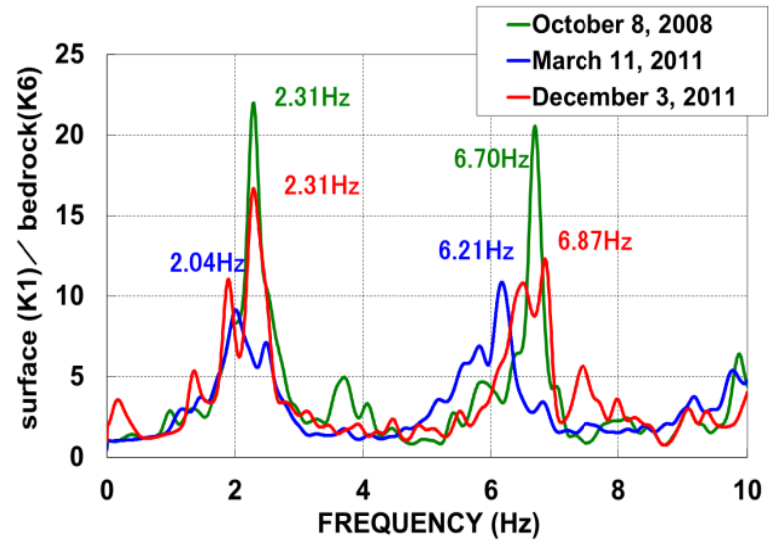

Fig. 5 The transfer functions (k1/k6), Comparison between EQ.3.11 and EQ.10.8 and EQ.12.03.

(1) Earthquake Observation Data

(2) Modal Analysis:

To grasp the dynamic characteristics of the ground using the observed earthquake data(Evaluate Eigen value \&

Eigen vector \& Transfer function between surface and base rock)

(3) Model identification analysis :

To carry out based on the results of

the modal analysis (Identified MCK) of the ground structure model

Fig. 6 Flow-chart of modal analysis and modal identification analysis.

mode constants (eigenvalue and eigenvector) obtained from observed records by least squares method. The equation of motion of the vibration system having a viscous damping is expressed in the following equation (Eq. (1)).

The system to treat in this analysis is assumed to behave according to Eq. (1).

$$
M \ddot{x}(t)+C \dot{x}(t)+K x(t)=f(t)
$$

where, $M, C$ and $K$ are mass, damping and rigidity matrix, respectively. Also, $\boldsymbol{x}(t)$ and $\boldsymbol{f}(t)$ are relative displacement and external force vector, respectively.

The mode constant can be obtained by evaluating the residuals between the solutions of Eq. (1) expressed to its explicit function and the observed records. As the solution of Eq. (1), the following 
relative acceleration $\ddot{x}(t)$ corresponding to the acceleration record to treat for the observed record is used.

$$
\ddot{x}(t)=2 \operatorname{Real}\left[\sum_{r=1}^{\mathrm{N}}\left\{\lambda_{r} \alpha_{r} e^{\lambda_{r} t}+u_{r}^{T} \beta(t)\right\} \lambda_{r} \mathbf{u}_{r}\right] \text { (2) }
$$

where, $\lambda_{r}$ and $\boldsymbol{u}_{r}$ are the $r$ th eigenvalue and eigenvector, respectively. The first term of the right-hand side of the upper expression is a general solution in the case of $f(t)=0$, and the secondary term is a particular solution. Vector $\boldsymbol{\beta}_{r}(t)$ satisfies the differential equation $\dot{\beta_{r}}(t)=\lambda_{r} \boldsymbol{\beta}_{r}(t)+f(t)$.

Because $\lambda_{r}$ is a nonlinear parameter for $\ddot{x}(t)$, it is calculated separately from a linear parameter $\boldsymbol{u}_{r}$. Firstly, as for $\ddot{x}(t)$, it is linearized with respect to the adjustment quantity $\Delta \lambda_{r}$ of $\lambda_{r}$ using Taylor's theorem, and the most probable value $\delta \lambda_{r}$ is obtained by minimizing the squared sum of the residuals between the analysis values (Eq. (2)) and the observed records, and the eigenvalue is improved in $\lambda_{r}^{\text {new }}=\lambda_{r}+\delta \lambda_{r}$. Subsequently $\boldsymbol{u}_{\boldsymbol{r}}$ is calculated based on that result. The calculations of $\delta \lambda_{r}$ and $\boldsymbol{u}_{r}$ are iterated until the rate of change of the squared residuals or $\delta \lambda_{r}$ converges in the predetermined value.

The transfer function of the system is expressed using the mode constants $\lambda_{r}$ and $\boldsymbol{u}_{\boldsymbol{r}}$ obtained from the modal analysis as follows.

$$
T(\omega)=\sum_{r} \frac{\omega^{2} \boldsymbol{u}_{r}^{T} M e}{i \omega-\lambda_{r}} \boldsymbol{u}_{r}+\boldsymbol{e}
$$

where, the modal participation function $\boldsymbol{u}_{r}^{T} M e \boldsymbol{u}_{r}$ is a constant independent of $M$. $\boldsymbol{e}$ is the unit vector.

\subsection{Numerical Model Identification Analysis Method}

The purpose of the identification analysis is to grasp dynamic characteristics of the object system depending on the Eq. (1) adjusted by evaluating the squared residuals between the solutions of Eq. (1) and the observed records. Where, as the observed record, the transfer function (Eq. (3)) obtained from the modal analysis is used.
By the way, because the transfer function $T(\omega, P)$ is nonlinear with respect to the material property value. So, in this method, the function is linearized with respect to the adjustment quantity by Taylor's theorem and is used, and the most probable value $\delta P_{n}$ is calculated in conditions of the residual minimization. However, that quantity is calculated indirectly as follows.

The linearized transfer function is expressed as follows by using the perturbation theory.

$$
\boldsymbol{T}(\omega, \boldsymbol{P}) \approx \boldsymbol{T}\left(\omega, \boldsymbol{P}_{\mathbf{0}}\right)+\sum_{n=1}^{N} \frac{\partial \boldsymbol{T}\left(\omega, \boldsymbol{P}_{\mathbf{0}}\right)}{\partial \boldsymbol{P}_{\boldsymbol{n}}} \Delta \boldsymbol{P}_{\boldsymbol{n}}
$$

where, $\partial \boldsymbol{T} / \partial \boldsymbol{P}_{\dot{\boldsymbol{n}}} \Delta \boldsymbol{P}_{n}$ is a function of the first order shift of $\lambda_{r}$ and $\boldsymbol{u}_{r}$ for the perturbation $\Delta \boldsymbol{P}_{\boldsymbol{n}}$, and it is a known quantity. $\boldsymbol{P}$ is the vector quantity denoting the material property value, and $\boldsymbol{P}_{\mathbf{0}}$ is the initial value. $N$ is number of the material properties. The expansion coefficient $a_{n}$ is obtained from the residual minimization, and the most probable value of the adjustment quantity $\delta \boldsymbol{P}_{\boldsymbol{n}}=a_{n} \triangle \boldsymbol{P}_{\boldsymbol{n}}$ is calculated.

The above-mentioned calculations are iterated until the rate of change of the squared residuals or the adjustment quantity $\partial \boldsymbol{P}_{\boldsymbol{n}}$ becomes lower than the predetermined value.

\subsection{The Ground Structure Models Estimated by Modal Analysis and the FEM Identified Analysis}

The main results were obtained as follows.

(1) Figs. 7 and 8 show the acceleration time-history and the transfer function $(\mathrm{k} 1 / \mathrm{k} 6)$ due to EQ.3.11 (Case2), comparison between the calculated result by modal analysis and the spectral ratio of observation result. These results also agree well with each other;

(2) Fig. 9 shows the transfer functions $(\mathrm{k} 1 / \mathrm{k} 6)$ of Case1, Case 2 and Case 3 , estimated by the modal analysis using observed data of EQ.1 \& EQ.2 and EQ.3.11 and EQ.12.03, respectively;

(3) Table 1 and 2 show the identified soil properties (shear wave velocity $(V s: \mathrm{m} / \mathrm{s})$ and damping factor: $h$ $(\%)$ ) of the three ground structure models, using EQ.1 

the 2011 off the Pacific Coast of Tohoku Earthquake

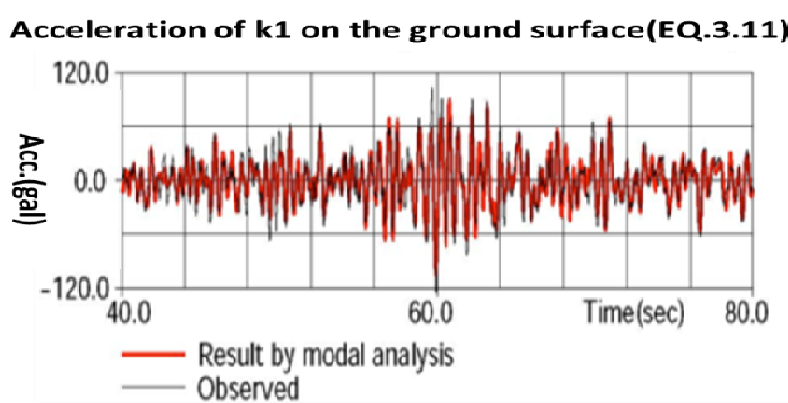

Fig. 7 The acceleration time history of k1 due to EQ.3.11, comparison between the results by modal analysis and observed one.

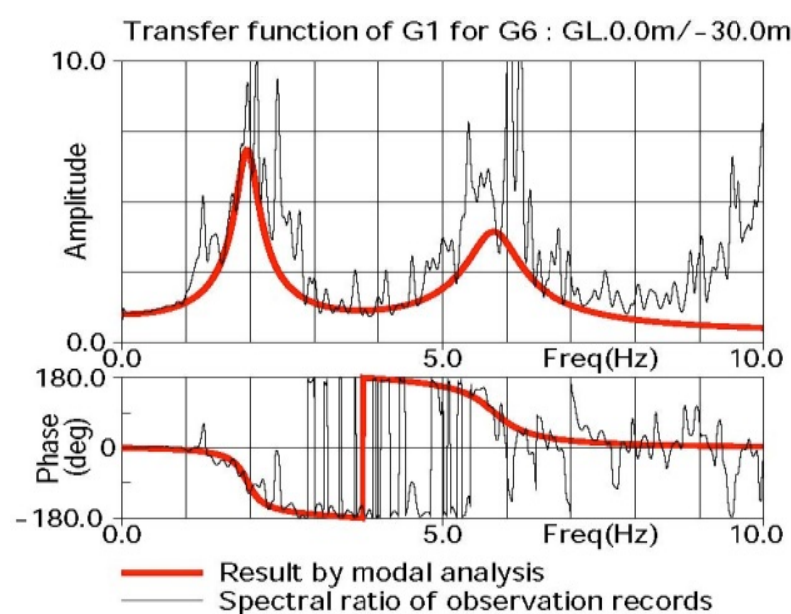

Fig. 8 The transfer function (k1/k6) due to EQ.3.11, comparison between the result by modal analysis and observation result.

\& EQ.2 (Case1), EQ.3.11 (Case2) and EQ.12.03 (Case3), respectively. Comparing Case1, Case2 and Case3, the identified properties of Case1 and Case3 were almost the same, but of those Case 2 were different from Case 1 and Case3. The soil properties $(V S \& h)$ of the third layer of the ground structure model were varied quietly. The ratio of $V S$ $($ Case $2 /$ Case 1$)=0.84$ (16\% decrease), and the ratio of $h($ Case $2 /$ Case 1$)=1.27(27 \%$ increase $)$ were evaluated.

From these results, the non-linear characteristics of the surface ground of Zushi-site were obtained during the 2011 off the Pacific coast of Tohoku Earthquake

\section{Seismic Response Analysis by TDAPIII}

(1) The seismic response analyses of the Zushi-site were performed by TDAPIII [3, 8], using the identified ground structure models (Case2) shown in Table 1.

(2) Two observed horizontal acceleration records (NS \& EW components) at k6 station of EQ.3.11 for input motions.

(3) Three-dimensional model was created based on

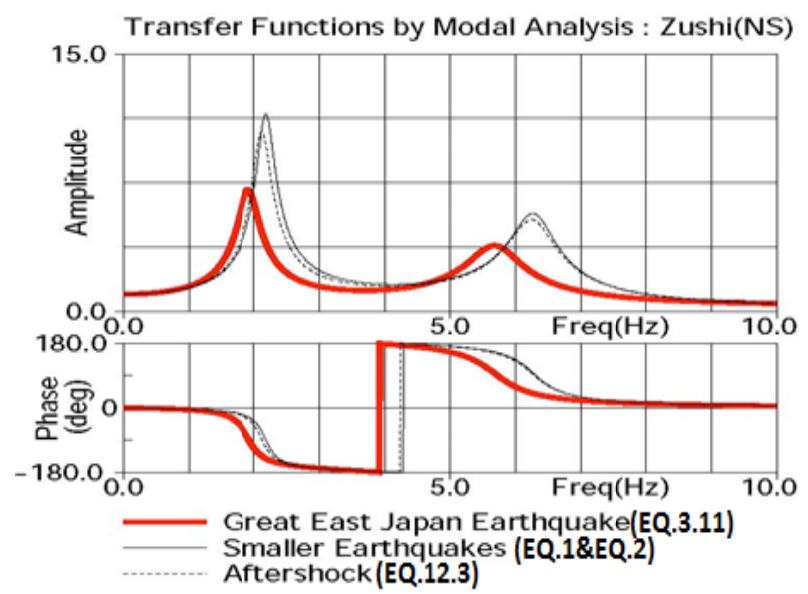

Fig. 9 The calculated transfer functions (k1/k6) Comparison EQ.3.11, EQ.1 \& EQ.2 and EQ.12.3.

Table 1 Identified Shear velocities (Vs: $\mathrm{m} / \mathrm{s}$ ) of ground structure models (Case1, Case2 and Case3).

\begin{tabular}{|c|c|c|c|c|c|}
\hline \multirow[b]{2}{*}{ Layer No. } & \multirow[b]{2}{*}{ Unit weight $\left(\mathrm{t} / \mathrm{m}^{3}\right)$} & \multicolumn{3}{|c|}{ Shear wave velocity $V s(\mathrm{~m} / \mathrm{s})$} & \multirow[b]{2}{*}{ Depth (m) } \\
\hline & & $\begin{array}{l}\text { Case } 1 * \\
\text { Smaller earthquakes before } \\
\text { EQ. } 3.11 \text { (EQ.1 \& EQ2) }\end{array}$ & $\begin{array}{l}\text { Case } 2 * * \\
\text { Great east Japan } \\
\text { earthquake (EQ3.11) } \\
\end{array}$ & $\begin{array}{l}\text { Case 3* } \\
\text { Small earthquake after } \\
\text { EQ.3.11 (EQ12.3) } \\
\end{array}$ & \\
\hline 1 & 1.70 & 150.1 & 150.0 & 150.0 & 1.0 \\
\hline 2 & 1.80 & Decrease & Increase & 134.1 & 4.0 \\
\hline 3 & 1.50 & 222.5 & 187.6 & 216.5 & 20.0 \\
\hline 4 & 1.90 & 237.6 & 228.9 & 236.0 & 24.0 \\
\hline 5 & 2.00 & 253.3 & 251.6 & 252.9 & 25.0 \\
\hline 6 & 2.00 & 400.8 & 400.4 & 400.7 & 26.0 \\
\hline 7 & 2.10 & 700.6 & 700.3 & 700.3 & 30.0 \\
\hline
\end{tabular}

$*$ Case $1 \cong$ Case $3,{ }^{*}$ Case $2<$ Case $1=$ Case $3($ Layer 3$)$. 

the 2011 off the Pacific Coast of Tohoku Earthquake

Table 2 Identified damping factors (h) ground structure models (Case1, Case2 and Case3).

\begin{tabular}{|c|c|c|c|c|c|c|c|}
\hline \multirow[b]{2}{*}{ Layer No. } & \multirow[b]{2}{*}{ Unit weight $\left(\mathrm{t} / \mathrm{m}^{3}\right)$} & \multicolumn{5}{|c|}{ Damping factor $\mathrm{h}(\%)$} & \multirow[b]{2}{*}{ Depth (m) } \\
\hline & & $\begin{array}{l}\text { Case } \\
\text { Small } \\
\text { EQ. } 3 \\
\end{array}$ & $\begin{array}{l}\text { rthquakes before } \\
\text { EQ.1 \& EQ2) }\end{array}$ & $\begin{array}{l}\text { Case } \\
\text { Great } \\
\text { earthc }\end{array}$ & $\begin{array}{l}\text { apan } \\
\text { (EQ3.11) }\end{array}$ & $\begin{array}{l}\text { Case } 3^{*} \\
\text { Small earthquake after } \\
\text { EQ.3.11 (EQ12.3) }\end{array}$ & \\
\hline 1 & 1.70 & 0.07 & Increase & 0.147 & Decrease & 0.07 & 1.0 \\
\hline 2 & 1.80 & 0.08 & & 0.14 & & 0.08 & 4.0 \\
\hline 3 & 1.50 & 0.11 & & 0.14 & & 0.12 & 20.0 \\
\hline 4 & 1.90 & 0.04 & & 0.04 & & 0.04 & 24.0 \\
\hline 5 & 2.00 & 0.03 & & 0.03 & & 0.03 & 25.0 \\
\hline 6 & 2.00 & 0.03 & & 0.03 & & 0.03 & 26.0 \\
\hline 7 & 2.10 & 0.03 & & 0.03 & & 0.03 & 30.0 \\
\hline
\end{tabular}

*Case1 $\cong$ Case3, **Case2 $>$ Case1 $\cong$ Case3 (Layer 1-3).

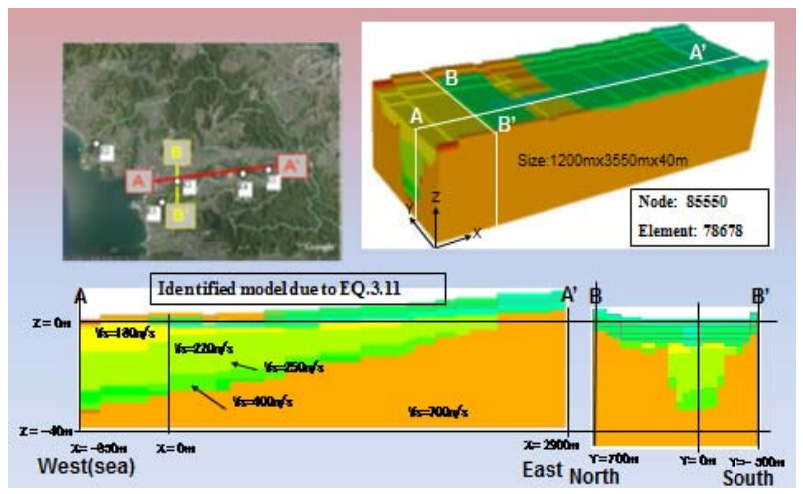

Fig. 10 Three-dimensional FEM model and geological sections A-A' \& B-B of Zushi-site.

two cross-sections (A-A' \& B-B') of the model, and the size is $1,200(\mathrm{Y}: \mathrm{m}) \times 3,550(\mathrm{X}: \mathrm{m}) \times 40(\mathrm{Z}: \mathrm{m})$, as shown in Fig. 10.

(4) The number of elements and nodes of the three-dimensional model is 78,678 and 85,550 , respectively.

(5) The thickness of all elements is $1.0 \mathrm{~m}$, and the width of all elements is $50 \mathrm{~m}$.

(6) The boundary condition of each side is roller, and bottom is fixed restraint.

\section{Results of Seismic Response Analysis by TDAPIII}

(1) Fig. 11 shows the transfer function $(\mathrm{k} 1 / \mathrm{k} 6)$ due to EQ.3.11, comparison between the calculated results and the observed ones. The calculated results agreed well with the observed ones.

(2) Figures12-a-12-c show the shear strain $\left(\gamma_{\mathrm{YZ}}\right)$ distributions in $\mathrm{X}(\mathrm{EW})$ direction of $\mathrm{A}-\mathrm{A}^{\prime}$ section, and those in Y (NS) direction of C-C' $(X=-400 \mathrm{~m})$ and B-B' section $(X=0)$, due to EQ.3.11, respectively.

The maximum shear strain occurred in the $3 \mathrm{rd}$ and the 4th layer, where the $V s$ were smaller than that of the other layers of the ground model.

(3) Fig. 13-(a) shows the surface horizontal accelerations of NS component of A-A' section from about $X=-700 \mathrm{~m}$ to $X=2,800 \mathrm{~m}$. The acceleration responses were also varied from 140 gal to 280 gal with the depth of the surface layer. The maximum value was obtained at west side of the surface ground where the depth of the surface layer the deepest.

(4) Fig. 13-(b) also shows the surface horizontal accelerations of NS component of B-B' section ( $X=0$ $\mathrm{m})$. The accelerations of the surface ground were from about 90 gal to 160 gal, varying with the depth of the surface layer. The maximum value obtained at the

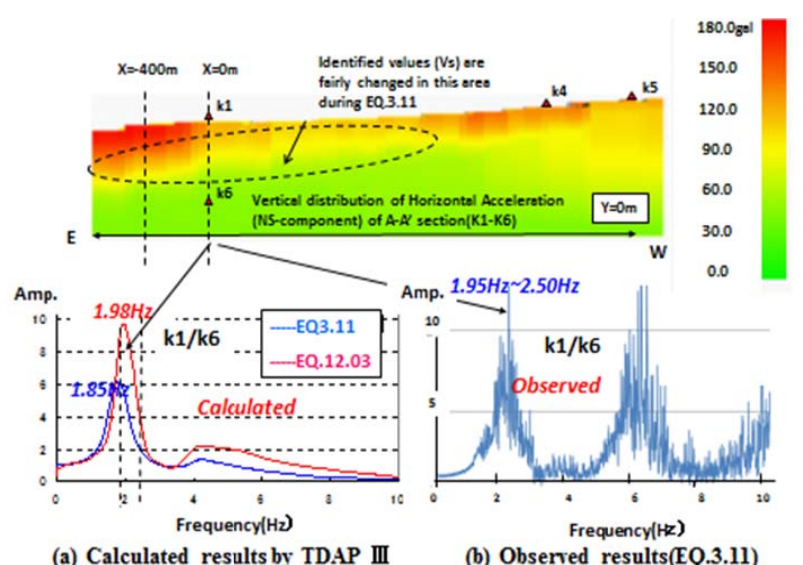

$\begin{array}{ll}\text { (a) Calculated results by IDAP III } & \text { (b) Observed results(EQ.3.11) }\end{array}$

Fig. 11 Transfer functions between the surface of ground (k1) and bedrock (k6: - $30 \mathrm{~m}$ ) due to EQ.3.11 (compared the observation results to the calculated ones). 


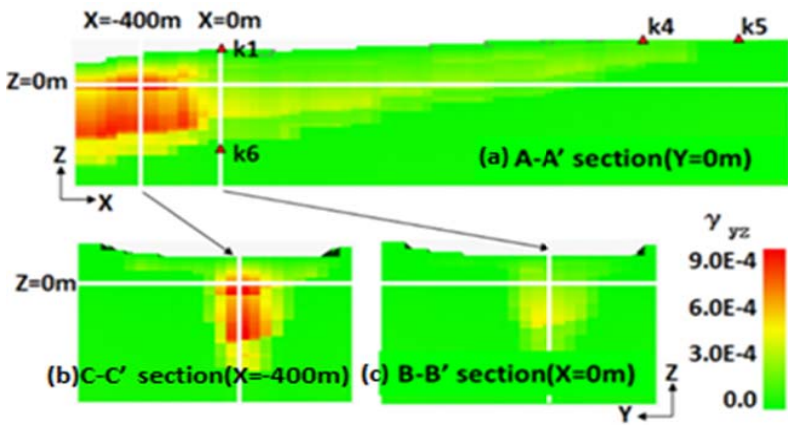

Fig. 12 Shear strain shear strain $\left(\gamma_{\mathrm{YZ}}\right)$ distributions of the surface ground of Zushi-site due to EQ.3.11.
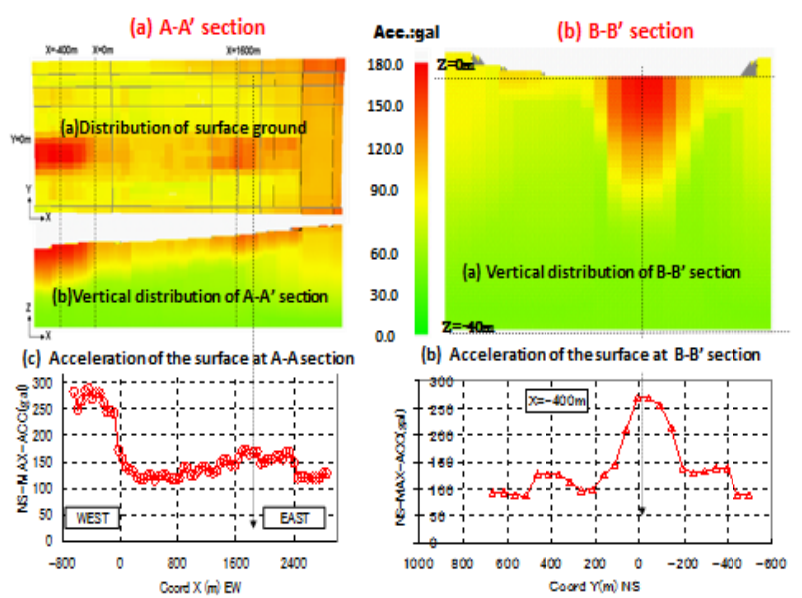

Fig. 13 Calculated acceleration responses (NS-component) of the surface ground of Zushi-cite due to EQ.3.11 ((a) A-A' section \& (b) B-B' section).

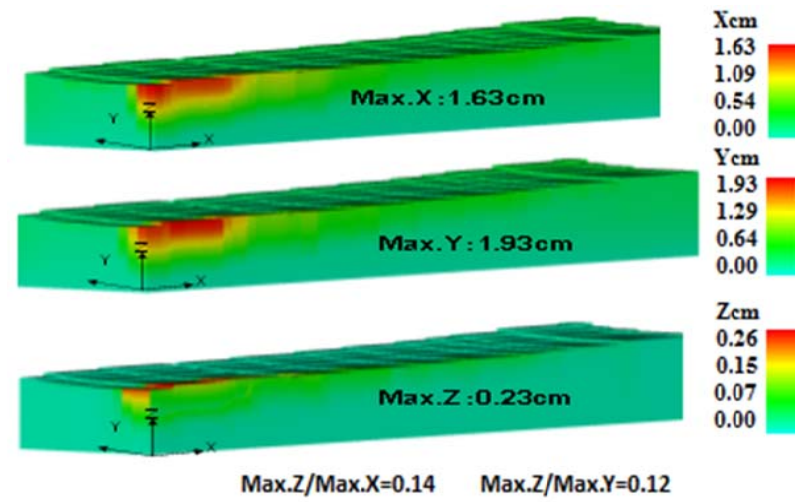

Fig. 14 The maximum displacement of NS (Y: cm), EW $(\mathrm{X}: \mathrm{cm})$ and $\mathrm{UD}(\mathrm{Z}: \mathrm{cm})$ components of the surface ground due to EQ.3.11.

center of the basin, where the depth of the surface layer was the deepest.

(5) Fig. 14 shows the maximum displacement of NS $(\mathrm{Y}: \mathrm{cm}), \mathrm{EW}(\mathrm{X}: \mathrm{cm})$ and UD $(\mathrm{Z}: \mathrm{cm})$ components of the surface ground. Maximum displacements of the surface ground are $1.63 \mathrm{~cm}$ (EW component), $1.93 \mathrm{~cm}$

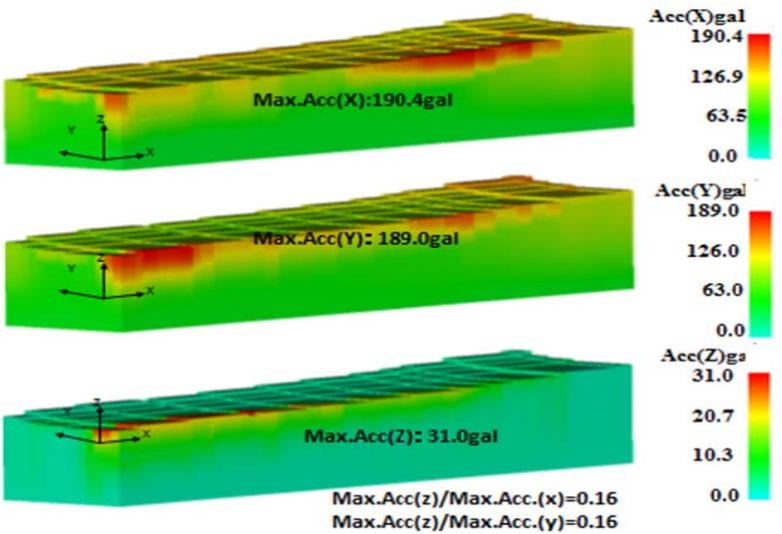

Fig. 15 The maximum horizontal accelerations responses (Acc(X: gal), Acc(Y: gal)), and vertical one (Acc (Z: gal)) of the surface ground of Zushi-cite due to EQ.3.11.

(NS component) and $0.23 \mathrm{~cm}$ (UD component) are obtained due to two horizontal input motions (EW = 39.6 gal, NS $=45.5$ gal). From the results, the vertical response (about $12 \%-14 \%$ of horizontal one) of the surface ground was occurred at the irregular ground due to the horizontal input motions.

(6) Fig. 15 shows the maximum horizontal accelerations (EW \& NS) and vertical one (UD) of the surface ground. Maximum accelerations of the surface ground which were 190.4 gal (EW component), 189.0 gal (NS component) and 31.0 gal (UD component), were also obtained due to two horizontal input motions $(\mathrm{EW}=39.6 \mathrm{gal}, \mathrm{NS}=45.5 \mathrm{gal})$.

From the results, the vertical response (about 16\% of horizontal one) of the surface ground was occurred at the irregular ground due to the horizontal input motions [8].

\section{Conclusion}

(1) The earthquake observation data were obtained on the surface ground at Zushi-site during the 2011 off the Pacific coast of Tohoku Earthquake. In the earthquake, the largest accelerations and the longest duration-time were recorded.

(2) The non-liner seismic response characteristics of the surface ground at Zushi-site were verified by the observed earthquake acceleration data and the modal analysis during the 2011 off the Pacific coast of Tohoku Earthquake. 

the 2011 off the Pacific Coast of Tohoku Earthquake

(3) The three dimensional ground structure models were examined and identified by the modal analysis and the FEM identification analysis using the past observed earthquake and the 2011 off the Pacific coast of Tohoku Earthquake acceleration data.

(4) The seismic responses of the surface ground Zushi-site during the 2011 off the Pacific coast of Tohoku Earthquake were verified using identified models and the observed earthquake data by TDAPIII.

(5) The vertical response of the surface ground was occurred at irregular ground due to the horizontal input motions.

(6) These results will be useful for seismic disaster mitigation and seismic design of the structures in Zushi-site.

\section{References}

[1] Iwatate, T., and Ohoka, A. 1996. "Surface Ground Motion Characteristics of Zushi-Site." In Proceedings of Eleventh World Conference on Earthquake Engineering, edited by Sociedad Mexicana de Ingenieria Sismica, A. C. Amesterdam: Elseiver.

[2] Iwatate, T., Oda, Y., and Ando, K. 2004. "Identification of Surface Ground Characteristics Using Horizontal Array Earthquake Observation Records and Its
Application.' In Proceedings of 13th World Conference on Earthquake Engineering, 2252.

[3] TDAPIII (Time Domain 3-Dimensional Dynamic Analysis Program). Ver. 3. 01. Theoretical Manual. 2008. ARK Information Systems Inc..

[4] Takahiro, I., Nobuaki, N., and Yoshiya, O. 2013. "The Seismic Characteristics of Surface Ground of Zushi-Site during the 2011 Japan Great Earthquake." Presented at the 11th SEGJ International Symposium, Yokohama, Japan.

[5] Koji, A., and Takahiro, I. 2003. "Identification of Dynamic Properties of Surface Ground Using Horizontal Earthquake Record and Its Application.” Journal of JSCE 63 (731): 213-29.

[6] Koji, A., Takahiro, I., and Yoshiya, O. 2008. "Identification of Dynamic Characteristics of Surface Ground Using Earthquake Observation Records and Its Application Surface Ground Characteristics of Zushi-City." Presented at the 14th World Conference on Earthquake Engineering, Beijing, China.

[7] Ando, K., and Iwatate, T. 1992. "Identification of Dynamic Properties of Vibrating System by Modal Analysis in the Time Domain and Its Application." Journal of JSCE 20 (450): 151-60.

[8] Takahiro, I., Yoshiya, O., Nobuaki, N., and Koji, A. 2012. "The Seismic Characteristics of Surface Ground of Zushi-Site during the 2011 Japan Great Earthquake." Presented at the 15th World Conference on Earthquake Engineering, Lisbon, Portugal. 